Original Research Article

\title{
Socio-demographic profile of multi-drug resistant tuberculosis patients and its association with severity of adverse drug reactions in DOTS plus centre at tertiary hospital in Himachal Pradesh, India
}

\author{
Anita Kumari ${ }^{1 *}$, Parveen K. Sharma $^{2}$, Dinesh Kansal ${ }^{3}$, Rekha Bansal ${ }^{4}$, Sumita Kumari ${ }^{5}$
}

${ }^{1}$ Department of Pharmacology, Dr. YSP Government Medical College, Nahan, Himachal Pradesh, India

${ }^{2}$ Department of Pharmacology, SLBS Government Medical College Mandi at Nechowk, Himachal Pradesh, India ${ }^{3}$ Department of Pharmacology, ${ }^{4}$ Department of Pulmonary Medicine, Dr. RP Government Medical College, Kangra, Tanda, Himachal Pradesh, India ${ }^{5}$ Department of Community Medicine, Dr. YSP Government Medical College, Nahan Himachal Pradesh, India

Received: 18 September 2018 Accepted: 22 October 2018

*Correspondence to: Dr. Anita Kumari, Email: anitakumarinegi@ gmail.com

Copyright: (C) the author(s), publisher and licensee Medip Academy. This is an openaccess article distributed under the terms of the Creative Commons Attribution NonCommercial License, which permits unrestricted noncommercial use, distribution, and reproduction in any medium, provided the original work is properly cited.

\begin{abstract}
Background: Multi-drug resistant tuberculosis has become major public health problem and obstacle to effective control of tuberculosis. Objectives was to study the socio-demographic profile of multi- drug resistant tuberculosis patients and its association with severity of ADR (adverse drug reactions) in DOTS plus centre at tertiary hospital in Himachal Pradesh.

Methods: It was a prospective observational study carried out from November 2012 to October 2013 on multi-drug resistant tuberculosis (MDR-TB) patients after approved from Institutional Ethics Committee.

Results: Out of 104 patients the mean age of patients was $39.9 \pm 14.26$ years. Majority of the patients were in the economically productive age groups. Multidrug resistant tuberculosis was more in male $(76 \%)$ than female $(24 \%)$ and $96 \%$ of patients were belonged to rural area. The educational status of the MDR-TB shows $24 \%$ patients were illiterate. $63.46 \%$ MDR-TB patients were underweight (BMI $<18.5 \%)$ according to WHO guidelines for obesity. Severity of ADR assessed by Hart wig and Siegel's scale showed $21 \%$ patients experienced mild ADRs, $49 \%$ patients had moderate and $17 \%$ patients had severe ADRs. Severity of ADR is seen more in male, economically productive age group, subjects on vegetarian diet, patients who were underweight $(\mathrm{BMI}<18.5 \%)$ and with lower educational status.

Conclusions: MDR-TB is a rapidly increasing health problem with major socioeconomic and individual consequences. Multi-drug resistant tuberculosis mainly affects middle age that is in the economically productive age group which hampers the social and economic development of individual, society and nation.
\end{abstract}

Keywords: Multi-drug resistant tuberculosis, Severity of adverse drug reactions, Socio-demographic profile

\section{INTRODUCTION}

Tuberculosis has remained major global problem and is ninth leading cause of death worldwide and leading cause from single infectious agent. ${ }^{1}$ In 2016, there were 60000 new case of drug resistant tuberculosis of which 49000 had multidrug resistant tuberculosis and $47 \%$ occurred in China, India and the Russian Federation. ${ }^{1}$ Poverty, under 
nutrition, HIV infection and smoking are major influence on tuberculosis epidemic and most of high burden countries have major challenges to reach targets. ${ }^{1}$ Patients with MDR-TB required longer duration and costly treatment resulting social isolation, loss of employment, long term socioeconomic effects and experience higher mortality. ${ }^{2}$ Adverse drug reactions on second line anti tuberculosis drugs and poor management of adverse drug reactions led to irregular adherence of treatment, increasing risk of default and may lead to death and permanent morbidity. ${ }^{3}$ Timely monitoring and management of ADR is required to prevent death and morbidity. Considering all these factors the present study was designed to study Socio-demographic profile of multidrug resistant tuberculosis patients and its association with severity of adverse drug reactions.

\section{METHODS}

It was prospective observational study. The study was carried out at DOTS Plus Centre Dr. Rajendra Prasad Government Medical College, Kangra at Tanda, Himachal Pradesh. Duration of the study was one year from November 2012 to October 2013. Multi- drug resistant tuberculosis patients fulfilled the inclusion and exclusion criteria.

\section{Inclusion criteria}

All multi-drug resistant tuberculosis patients registered for category-IV treatment were given written Informed consent.

\section{Exclusion criteria}

Patients were not given written informed consent to participate in the study.

\section{Data collection}

The written informed consent was obtained from all the patients. A questionnaire was developed through review of literature. Data was collected into two parts:

- Socio demographic profile: age, sex, education, occupation, family history of $\mathrm{TB}$, diet pattern, and BMI

- $\quad$ Severity of ADR assessed by Hart twig scale and Causality was assessed by as per WHO Probability scale. $^{4,5}$

Ethical clearance was approved by Protocol Review Board and Institutional Ethics Committee DRPGMC Tanda, Himachal Pradesh, India.

\section{Statistical analysis}

Data analysis was done using SPSS software version 17. Descriptive analysis was done (mean, proportion and percentages) for demographic variable. Association between socio-demographic variables and severity of ADR was analysis by Chi square test. $\mathrm{P}<0.05$ was considered as statistical significant.

\section{RESULTS}

A total of 104 multi-drug resistant tuberculosis patients were enrolled. Youngest patient in the study was 13 years and oldest was 85 years of age and mean age of patients was $39.9 \pm 14.26$ years.

\section{Socio-demographic profile}

The distribution of the subject according to their age groups shows majority of the patients were in the economically productive age groups (Table 1).

Table 1: Age distribution of multi-drug resistant tuberculosis patients.

\begin{tabular}{|ll|l|}
\hline Age & Frequency & Percentage \\
\hline$<16$ & 4 & 3.8 \\
\hline $16-25$ & 13 & 12.5 \\
\hline $26-45$ & 54 & 51.9 \\
\hline$>45$ & 33 & 31.7 \\
\hline Total & 104 & 100 \\
\hline
\end{tabular}

Multi-drug resistant tuberculosis was more in male $(76 \%)$ than female $(24 \%)$ and the male to female ratio was $3: 1$. $96 \%$ of patients were belonged to rural area and $4 \%$ to urban area. $86 \%$ patients did not have family history of tuberculosis and only $14 \%$ have family history of tuberculosis and $74 \%$ patients were non-vegetarian diet and $26 \%$ were vegetarian diet. The occupational profile of patients shows majority of them were $(56.7 \%)$ farmers followed by skilled professionals $(15.4 \%)$, housewives were $12.5 \%$, unskilled worker $7.7 \%$ and $7.7 \%$ were students (Figure 1).

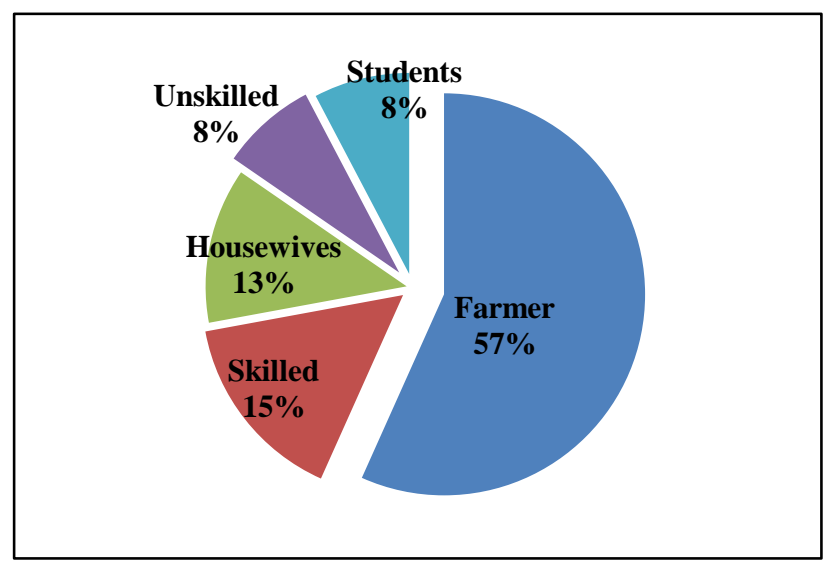

Figure 1: Occupation status of multi- drug resistant tuberculosis patients.

The educational status of the MDR-TB shows $24 \%$ patients were illiterate and rest distributed in all the subclasses but less of them are graduate and above (Figure- 
2). $63.46 \%$ MDR-TB patients were underweight $(\mathrm{BMI}<18.5 \%)$, none of the patients was obese $(\mathrm{BMI}>30)$ according to WHO guidelines for obesity. ${ }^{6}$

\section{Severity of ADR}

Severity assessment using Hart wig and Siegel's scale showed $21 \%$ patients experienced mild ADRs, $49 \%$ patients had moderate, $17 \%$ patients had severe ADRs and $13 \%$ patients does not experience any ADR shown in (Figure 3).

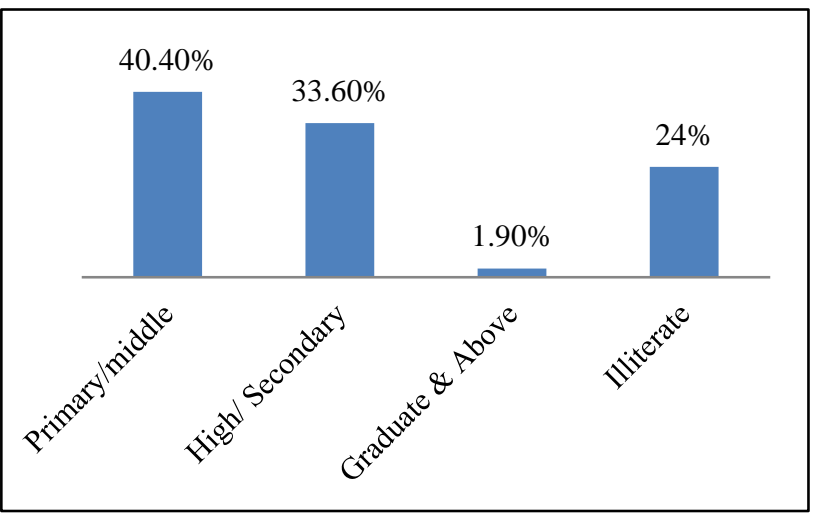

Figure 2: Education status of multi-drug resistant tuberculosis patients.
Association between severity of $A D R$ with the sociodemographic factors

Severity of ADR is seen more in male, economically productive age group, subjects on vegetarian diet, patients who were underweight $(\mathrm{BMI}<18.5 \%)$ and with lower educational status (Table 2). Association between severity of ADR with BMI and educational status was statistically significant (Table 2).

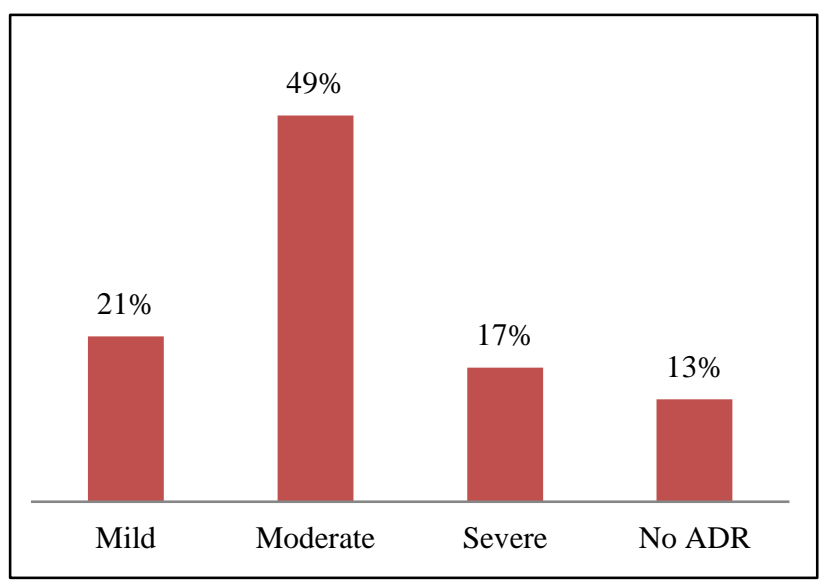

Figure 3: Severity adverse drug reactions multi- drug resistant tuberculosis.

Table 2: Association between demographic profile and severity of ADR.

\begin{tabular}{|c|c|c|c|c|c|c|}
\hline \multirow{2}{*}{ Demographic Profile } & & \multicolumn{5}{|c|}{ Severity of adverse drug reaction } \\
\hline & & $\begin{array}{l}\text { No } \\
\text { (n)ADR }\end{array}$ & $\begin{array}{l}\text { Mild } \\
\text { (n) }\end{array}$ & $\begin{array}{l}\text { Moderate } \\
\text { (n) }\end{array}$ & $\begin{array}{l}\text { Severe } \\
\text { (n) }\end{array}$ & Chi Square Test \\
\hline \multirow{4}{*}{ Age } & $<16$ & 1 & 0 & 3 & 0 & \multirow{4}{*}{$\begin{array}{l}\chi^{2} 9.886 \\
\mathrm{P}(0.360)\end{array}$} \\
\hline & $16-25$ & 3 & 3 & 6 & 1 & \\
\hline & $26-45$ & 9 & 12 & 26 & 7 & \\
\hline & $>45$ & 1 & 7 & 16 & 9 & \\
\hline \multirow{2}{*}{ Sex } & Male & 10 & 17 & 38 & 14 & \multirow{2}{*}{$\begin{array}{l}\chi^{2} 0.617 \\
P(0.892)\end{array}$} \\
\hline & Female & 4 & 5 & 13 & 3 & \\
\hline \multirow{3}{*}{ BMI } & $<18.5 \%$ & 14 & 16 & 27 & 9 & \multirow{3}{*}{$\begin{array}{l}\chi^{2} 15.964 \\
\mathrm{P}(0.014)^{*}\end{array}$} \\
\hline & $18.5-24.9 \%$ & 0 & 4 & 23 & 7 & \\
\hline & $25-29.9 \%$ & 0 & 2 & 1 & 1 & \\
\hline \multirow{2}{*}{ Family history of TB } & Absent & 12 & 19 & 45 & 14 & \multirow{2}{*}{$\begin{array}{l}\chi^{2} 0.390 \\
\mathrm{P}(0.942)\end{array}$} \\
\hline & Present & 2 & 3 & 6 & 3 & \\
\hline \multirow{2}{*}{ Dietary history } & Vegetarians diet & 11 & 16 & 37 & 13 & \multirow{2}{*}{$\begin{array}{l}x^{2} 0.281 \\
P(0.964)\end{array}$} \\
\hline & Non- vegetarians diet & 3 & 6 & 14 & 4 & \\
\hline \multirow{2}{*}{ Education } & Lower & 10 & 11 & 30 & 16 & \multirow{2}{*}{$\begin{array}{l}x^{2} 9.690 \\
\mathrm{P}(0.021)^{*}\end{array}$} \\
\hline & Upper & 4 & 11 & 21 & 1 & \\
\hline
\end{tabular}

$\mathrm{P} *<0.005$

\section{Causality assessment}

According to WHO-UMC scale causality assessment was done among the MDR-TB patients that shows $82 \%$ patients were possible in nature followed by $4 \%$ patients were certain and $1 \%$ probable/ likely (Table 3 ).

\section{DISCUSSION}

MDR-TB is a rapidly increasing health problem with major socio-economic and individual consequences. In the present study multi-drug resistant tuberculosis were more in male $(76 \%)$ than female $(24 \%)$ the mean age of patients 
was $39.9 \pm 14.26$ years. This shows that multi-drug resistant tuberculosis is a disease of middle aged males who are in the economically productive age group. Most of the studies conducted in India multi-drug resistant tuberculosis is more prevalent in males with mean age ranging from 32 to 37 years. $^{7-9}$ This could be due to tuberculosis is more prevalent in males because of their high risk behavior such as smoking, alcoholism as compared to females. Though in this study all of them had stopped smoking and alcohol by the time they were diagnosed as having multi-drug resistant tuberculosis.

Table 3: Causality assessment of ADRs using WHO Probable Scale.

\begin{tabular}{|lll|}
\hline Causality & No of patients & Percentage \\
\hline No ADR & 14 & 13 \\
\hline Certain & 4 & 4 \\
\hline Probable/Likely & 1 & 1 \\
\hline Possible & 85 & 82 \\
\hline Total & 104 & 100 \\
\hline
\end{tabular}

There were $96 \%$ of multi-drug resistant tuberculosis patients in present study belonged to rural area and only $4 \%$ were residing in urban areas. This is on expected lines as $89.7 \%$ population of Himachal Pradesh resides in rural areas (census 2011). ${ }^{10}$

In this study, about $76 \%$ were literate and $24 \%$ were illiterate Further, it was found that the patients of multidrug resistant tuberculosis were distributed in all educational status but lowest in graduate and above. Level of education is important factors for knowledge, attitude, prevention and treatment outcome of disease. Majority of the patients in this study were farmers this may be because most of the population in the area is involved in agriculture and other manual activities. In studies conducted in India also shows a trend of drug resistance in tuberculosis being more common in lowest educational status. ${ }^{8,11} 63.46 \%$ patients in this study were underweight $(\mathrm{BMI}<18.5 \%)$ and finding show in other study conducted in Kolkata $59.9 \%$ patients were underweight. ${ }^{12}$ This could be due to poor nutritional status.

Only $14 \%$ patients had family history of tuberculosis and other study conducted by Wahab et al $23.3 \%$ patients had family history tuberculosis. ${ }^{13}$ Family history is important factor in transmission of disease. This could be social stigma attached to disease.

Limitations of the study included population was only those taking treatments from governments DOTs Plus health centre.

\section{Recommendations}

There is a need of health awareness, education and communication activities so as to make them aware of common symptoms, early diagnosis and treatment and also to avail the facilities at government's center.

\section{ACKNOWLEDGEMENTS}

Authors would like to thank all faculty member and resident of Department of Pharmacology and Pulmonary Medicine Dr RPGMC Tanda for support and help.

\section{Funding: No funding sources \\ Conflict of interest: None declared}

Ethical approval: The study was approved by the Institutional Ethics Committee of DRPGMC Tanda, Himachal Pradesh, India and Protocol Review Board

\section{REFERENCES}

1. World health organization, Global TB report 2017. Available at: www.who.Int/tb/Publication/global_report2017/en/in dex.html. Accessed on 08 July 2018.

2. Morris MD, Quenza L, Bhat P, Moser K, Smith J, Perez H, et al. Social, economic and psychological Impacts of MDR-TB treatment. Int J Tuberc Lung Dis. 2013;17(7): 954-60.

3. Central TB Division (CTD), Directorate General of Health services, Ministry of Health and Family Welfare, Government of India, Programmatic Management of Drug Resistant TB (PMDT) Guidelines 2017. CTD, New Delhi.

4. Hartwig SC, Siegel J, Schneider PJ. Preventability and severity assessment in reporting adverse drug reactions. Am J Hosp Pharm. 1992;49:2229-32.

5. The use of the WHO-UMC system for standardized case causality assessment. Available at: http://www.who.int/medicines/areas/quality_safety/sa fety_efficacy/WHOcausality_assessment.pdf.Accesse d on 9 September 2018.

6. World health organization. Fact sheet: obesity and overweight; 2018. Available at: http://www.who.int/en/news-room/factsheets/detail/obesity-and-overweight. Accessed on 9 September 2018.

7. Sharma SK, Kumar S, Saha PK, George N, Arora SK, Gupta D, et al. Prevalence of multidrug-resistant tuberculosis among category II pulmonary tuberculosis patients. Indian J Med Res. 2011;133:312-5.

8. Bhatt G, Vyas S, Trivedi K. An epidemiological study of multi drug resistant tuberculosis. Indian J Tuberc. 2012;59(1):18-27.

9. Thomas A, Ramachandran R, Rehaman F, Jaggarajamma K, Santha T, Selvakumar N, et al. Management of multi drug resistance tuberculosis in the field. Indian J Tuberc. 2007;54:117-24.

10. Himachal Pradesh population census; 2011. Available at: https://www.censusindia.co.in/states/himachalpradesh. Accessed on 9 September 2018. 
11. Mishra VK, Gupt P, Pachar P, Jangir SK, Gupta RC, Gour N. A study to assess the profile of multidrugresistant tuberculosis (MDR-TB) in tertiary care hospital setting. Sch J App Med Sci. 2016;4(3):82027.

12. Mukherjee P, Karmakar PR, Basu R, Lahiri SK. Sociodemographic and clinical profile of multi drug resistant tuberculosis patients: a study at drug resistant tuberculosis. JDMS. 2015;14(8):52-8.

13. Wahab F, Ashraf S, Khan N, Anwar R and Afridi MZ. Risk factors for multi-drug resistant tuberculosis in patients. J Coll Physicians Surg Pak. 2009;19(3):1624.

Cite this article as: Kumari A, Sharma PK, Kansal D, Bansal R, Kumari S. Socio-demographic profile of multi-drug resistant tuberculosis patients and its association with severity of adverse drug reactions in DOTS plus centre at tertiary hospital in Himachal Pradesh, India. Int J Basic Clin Pharmacol 2018;7:2342-6. 